\title{
Concepções de educação e educação ambiental nos trabalhos do I EPEA.
}

\author{
Rosa Maria Feiteiro Cavalari, Luiz Carlos Santana, \\ Luiz Marcelo de Carvalho. ${ }^{1}$
}

resumo A necessidade de questionar o "conceito essencial da educação" e de assumir uma postura crítica em face das "concepções usualmente presentes a respeito dos fins da educação" motivou o desenvolvimento desta investigação. Nossa intenção é contribuir para uma reflexão sobre os fundamentos da razão e das práticas educativas de maneira geral e da educação ambiental em especial. Assim, entendemos como significativo investigar as concepções de educação e educação ambiental presentes nos trabalhos de pesquisa e nos ensaios críticos apresentados no I Encontro de Pesquisa em Educação Ambiental (julho/2001). As questões que orientaram esta investigação podem ser assim sistematizadas: que concepções de educação e educação ambiental podem ser identificadas nos trabalhos apresentados no I EPEA? Que elementos ou indícios podem ser evidenciados nos textos que permitem a identificação de tais concepções? Tanto a coleta de dados como a análise destes foram realizadas a partir dos pressupostos da "análise de conteúdo", privilegiando o desenvolvimento de análises temáticas. A dimensão política do processo educativo, consubstanciada a partir das perspectivas de transformação social e da construção do ideal de cidadania, destaca-se nos textos analisados. A concretização de tal perspectiva, segundo os textos, deve considerar nas justificativas, objetivos, diretrizes e/ou princípios o processo de participação, a interdisciplinaridade, o desenvolvimento de valores, as relações local-global-local, o potencial de conflitos socioambientais, entre outros. Considerando o risco da presença de concepções nos textos de pesquisas em educação ambiental que se aproximam de uma perspectiva "tradicional" ou "tecnicista", associadas, às vezes, a

1 Professores do Departamento de Educação do Instituto de Biociências da UNESP, Campus de Rio Claro. Programa de Pós-Graduação em Educação - Núcleo Temático Educação Ambiental. IB, UNESP, Rio Claro. rosamfc@,rc.unesp.br; luizcs@rc.unesp.br; 1marcelo@rc.unesp.br 
um processo de instrumentalização da educação ambiental, assumindo, assim, uma perspectiva pragmática, entendemos ser necessário a busca da perspectiva humanizadora da educação.

palavras-chave: propósitos da educação, educação ambiental, trabalhos de pesquisa

abstract This research has been motivated by the necessity of understanding the essential concept of education and of having critical attitudes related to the common sense about the aims of education. Researches related to the concepts of education and environmental education can help us to understand the fundamental principles that are being chosen to justify and to carry out environmental education programs. So, trying to understand tendencies in environmental education researcher's conceptions in Brazil we carried out an analysis of the articles presented in The First Environmental Education Research Meeting (I EPEA). The main questions proposed are: 1 - what conceptions of education and environmental education can be identified in the articles presented in I EPEA? 2 - What evidences can be raised from these articles to help us to identify such conceptions? Through content analysis we tried to identify meaningful excerpts to the research purposes and to categorize them in a thematical process. The political dimension of education, linked to the process of social transformation and citizenship, was one of the main aspects find out in the articles. Participation, interdisciplinarity, values, the relationship between local and global aspects of environmental issues and controversial issues were objectives or methodological principles presented in I EPEA articles. Nevertheless, it is relevant to point out that we could find some elements that permit us to link them to a traditional view of education or a view that goes in the direction of technicality in education. Risks of a pragmatic view or of an instrumentalism conception of environmental education present in these articles are mentioned.

key words: aims of education, environmental education, articles

\title{
Introdução
}

\author{
O entendimento da educação como responsável diretamente \\ pelo processo de humanização é praticamente consenso entre os
}


teóricos da educação. Já se tornaram célebres as reflexões de Rousseau e de Kant a esse respeito. Esses pensadores enfatizam a fragilidade e a precariedade da condição do homem no nascimento e a transformação operada pela educação no transcorrer de sua existência. De acordo com Rousseau, "nascemos fracos, precisamos de força; nascemos desprovidos de tudo, temos necessidade de assistência; nascemos estúpidos, precisamos de juízo. Tudo o que não temos ao nascer, e de que precisamos adultos, é nos dado pela educação".(ROUSSEAU, 1973, p. 10).

Kant seguindo a mesma linha de raciocínio, além de afirmar que "o homem é a única criatura que precisa ser educada", afirma que "o homem não pode tornar-se verdadeiro homem senão pela educação. Ele é aquilo que a educação dele faz [...]" (KANT, 2002, p 11 e 15 respectivamente).

Cumpre destacar que a ênfase e o papel atribuídos por esses pensadores à educação como única responsável pelo processo de formação humana foram posteriormente relativizados por outros pensadores que, sem desmerecer o papel e a importância da Educação, defendem que outras práticas sociais devem ser consideradas para o processo de humanização.

Em que pese essa observação, a educação como processo de formação humana pode ser entendida como o esforço para ultrapassar no indivíduo os limites da sua natureza e lhe dar uma outra conformação, uma "segunda natureza". "Esta é uma responsabilidade a ser atribuída ao Educador” (RODRIGUES, 2001, p. 243).

Ao realizar tal tarefa, o educador o faz com base na atividade prática. A Educação, assim como toda a expressão da existência humana, é construída pela prática. No entanto, para que essa prática não resulte em uma atividade meramente mecânica, ela não pode prescindir da teoria (SEVERINO, 2002).

Assim sendo, a base do fenômeno educativo são as práticas concretas; no entanto, para poder se manifestar de forma significativa, essa prática precisa da teoria. A prática humana para ultrapassar sua dimensão mecânica precisa se expressar por meio do "pensamento e do conceito", 
[...] a atividade teórica ganha sentido na medida em que se faz como intencionalização da prática, que opera quando efetiva o esclarecimento. No âmbito educacional, a teoria tem por finalidade esclarecer os elementos envolvidos na prática, dando-lhes sentido norteador e referência do processo, evitando que a intervenção educativa se torne puramente mecânica" (p. 9).

Ao intencionalizar sua prática, ou seja, ao dar uma significação conceitual e valorativa para sua ação, o educador o faz a partir de determinadas idéias, crenças, valores, ideologias, conhecimentos e saberes, vale dizer, a partir de determinadas concepções. A intencionalização da prática pedagógica se realiza, portanto, a partir de concepções. Tais concepções, no entanto, nem sempre se expressam de maneira clara e transparente. Nesse sentido, tem se imposto cada vez mais para os estudiosos da educação a importância de investigações que busquem compreender as concepções presentes, seja no processo educativo, seja na produção teórica elaborada sobre educação.

Rodrigues (2001) alerta para o risco que pode significar o entendimento de que "as questões referentes à Educação se acham suficientemente esclarecidas". Tal entendimento, de acordo com o autor, além de não contribuir para o avanço do conhecimento, uma vez que não coloca sob suspeita conclusões tidas como verdadeiras, acaba por desembocar na idéia de que a investigação sobre o fenômeno educativo pode abrir mão da reflexão teórica e se concentrar apenas naquilo que é "prático e objetivo". Assim sendo, "a investigação se limitaria às considerações de natureza pragmática e utilitária".

Contrapondo-se a essa idéia, o autor defende a necessidade da reflexão sobre o "conceito essencial da educação". Para tanto, torna-se necessário criticar as "concepções do senso comum a respeito dos fins da educação" com o objetivo de elucidar "os fundamentos da razão educativa”. Nesse sentido, segundo o autor, é importante o questionamento sobre a pertinência da justificativa que tem sido freqüentemente difundida para a ação educativa, qual seja, a "tarefa prática de preparar os indivíduos para a vida social". Tal justificativa, 
se assumida como premissa, além de instituir "um parâmetro universal sobre os fins da educação", pode levar à conclusão que "tanto o conceito de educação quanto os fins da ação educativa já são suficientemente conhecidos". (RODRIGUES, 2004, p.234).

Tendo como referência as reflexões empreendidas por Severino e Rodrigues, podemos compreender que subjacentes às produções teóricas e às práticas educativas existem diferentes concepções de Educação e de Educação Ambiental. Podemos compreender, também, que essas concepções e as implicações delas decorrentes nem sempre estão suficientemente explicitadas e esclarecidas. Dessa forma, as questões que orientaram o desenvolvimento dessa investigação poderiam ser assim sistematizadas: que concepções de educação e educação ambiental podem ser identificadas, explícita ou implicitamente, nos trabalhos apresentadas no I EPEA? Que elementos ou indícios podem ser evidenciados nos textos que permitem a identificação de tais concepções?

Esperamos, assim, que respostas a questões dessa natureza e as análises aqui empreendidas possam contribuir para o debate acerca das reflexões sobre aspectos teórico-metodológicos das propostas relacionadas com educação ambiental.

\section{1 - Procedimentos de pesquisa}

Considerando as questões de pesquisa e os objetivos definidos para essa investigação, entendemos ser a abordagem qualitativa a que oferece maiores possibilidades para o desenvolvimento da pesquisa. De acordo com Bogdan e Biklen (1994), os investigadores qualitativos "tentam compreender o processo mediante no qual as pessoas constroem significados e descrever em que consistem estes mesmos significados". ( p. 70).

A investigação qualitativa, de acordo com esses autores, é dotada de cinco características; no entanto, alertam para o fato de que nem todos os estudos qualitativos atendem a essas características com 
igual intensidade e na mesma proporção. São as seguintes as características da investigação qualitativa:

1) [...] a fonte direta de dados é o ambiente natural, constituindo o investigador o instrumento principal; 2) a investigação qualitativa é descritiva; 3) os investigadores qualitativos interessam-se mais pelo processo do que simplesmente pelos resultados ou produtos; 4) os investigadores qualitativos tendem a analisar os seus dados de forma indutiva; 5) o significado é de importância vital na abordagem qualitativa". (p. 47 a 50).

Para a análise das concepções de Educação e de Educação Ambiental presentes nos trabalhos apresentados no I EPEA, adotamos como procedimento metodológico a "Análise de Conteúdo" conforme proposta por BARDIN, (1991). A análise de conteúdo compreende três fases:

-a pré-análise;

-a exploração do material;

- tratamento dos resultados, a inferência e a interpretação"(BARDIN, p. 95).

A pré-análise "é a fase de organização propriamente dita.Corresponde a um período de intuições, mas, tem por objetivo tornar operacionais e sistematizar as idéias iniciais, de maneira a conduzir a um esquema preciso do desenvolvimento das operações sucessivas, num plano de análise". Esta primeira fase, de modo geral, tem triplo objetivo, a saber, a escolha dos documentos a serem submetidos à analise, a formulação das hipóteses e dos objetivos e a elaboração de indicadores que fundamentem a interpretação final" (BARDIN, p.95).

Assim sendo, na fase da pré-análise procedemos à leitura dos trabalhos na íntegra e definimos o corpus documental. Cumpre destacar que embora tenham sido apresentados no I EPEA 79 trabalhos, o corpus documental objeto de nossa análise foi constituído por 76 trabalhos, sendo 70 relatos de pesquisa e 6 ensaios críticos. Os outros três trabalhos não integraram esse corpus por não se enquadrar 
nas categorias apresentadas acima, ou seja, um era relativo a um banco de dados como ferramenta para o desenvolvimento de pesquisas sobre educação ambiental os outros dois são descrições de sistemas computacionais utilizados em programas e projetos de educação ambiental.

Cumpre destacar, ainda, que essa primeira leitura dos trabalhos pode ser caracterizada como "flutuante", tal como designada por Bardin, isto é, realizada com o objetivo de "estabelecer contato com os documentos a analisar" e de "conhecer o texto deixando-se invadir por impressões e orientações”. (BARDIN, p. 96).

Posteriormente, novas leituras foram realizadas, de forma atenta, buscando estabelecer as categorias de análise. Foi elaborada uma ficha de leitura na qual se identificou o trabalho, o autor, e foram registradas as passagens ou excertos que, de alguma forma, ofereciam elementos para se identificar concepções de educação e educação ambiental. No entanto, como era de se esperar, as concepções sobre educação e educação ambiental nem sempre se apresentam de forma explícita e sistematizada nos textos, mas, na maioria das vezes, refletidas nas afirmações que são apresentadas quando se procura de alguma forma caracterizar esses processos. Sendo assim, passagens ou excertos desses textos em que se procura justificar o significado filosófico, social ou cultural do processo educativo relacionado com a temática ambiental, suas finalidades, objetivos, diretrizes foram identificados e constituíram-se em material privilegiado para a nossa análise. Da mesma forma, e com o mesmo objetivo, procuramos identificar e selecionar referências ou passagens nesses textos que fizessem menção a elementos ou pressupostos em relação ao processo de ensino e de aprendizagem ou em relação a princípios e procedimentos metodológicos..Os elementos identificados nesse processo foram agrupados a partir de determinadas categorias que orientaram a sistematização e a análise dos dados.

Portanto, o procedimento de análise, por nós utilizado, foi o de "análise por categorias" ou "análise categorial". De acordo com Bardin (1991), "a categorização é uma operação de classificação de elementos constitutivos de um conjunto, por diferenciação e, seguidamente, por 
reagrupamento segundo o gênero (analogia), com critérios previamente definidos".(p. 117).

Ainda de acordo como a autora, existem várias possibilidades de categorização. Dentre as diferentes possibilidades de categorização existentes, optamos pela investigação dos temas, ou análise temática. "Fazer uma análise temática, consiste em descobrir os 'núcleos de sentido' que compõem a comunicação e cuja presença, ou freqüência de aparição podem significar alguma coisa para o objetivo escolhido"(p. 105).

Sendo assim, para a apresentação dos resultados da análise efetuada parece relevante assinalar que os excertos apresentados no texto não são tomados como representativos da "maioria" dos trabalhos apresentados no I EPEA. O critério para a escolha desses excertos, considerando o procedimento de análise que utilizamos, foram os significados por nós reconhecidos como relevantes no processo de construção das concepções sobre educação e educação ambiental. A tentativa, quando do processo de análise foi, assim, a de identificar, pela presença ou ausência, diferentes elementos ou dimensões que têm sido utilizados pela comunidade de pesquisadores e educadores como fundamentos teórico-metodológicos da educação e da educação ambiental.

Fizemos a opção de identificar os excertos citados neste texto por meio do número do trabalho registrado no CD Rom que editou os Anais do evento. Nesse CD Rom estão publicados, na íntegra, os trabalhos de pesquisa e os ensaios críticos apresentados no evento, identificados pelas letras $\mathbf{T r}$, seguidas do número de ordem em que foram gravados no CD Rom.

\section{2 - A Dimensão política do processo educativo: Transformação Social e a Construção da Cidadania}

O processo de análise dos relatos de pesquisas e ensaios críticos apresentados no I EPEA teve como foco, como já explicitado, a tentativa de identificar indícios que nos possibilitassem construir um quadro em relação a possíveis concepções sobre educação e educação 
ambiental. Dessa forma, os primeiros esforços realizados foram no sentido de identificar passagens que explicitavam de forma ora mais sistematizada ora a partir de elementos diversos do processo educativo ou mesmo da prática educativa uma dada concepção relacionada a tais processos.

Como primeiro resultado de nossa análise destacamos o fato de que não foi possível identificar qualquer referência explícita ou implícita ao processo educativo, em seu sentido mais amplo, ou ao processo educativo quando relacionado à temática ambiental em 16 dos textos analisados, dentre um total de 76 . No conjunto, estes são trabalhos de pesquisa ou ensaios críticos que tiveram como objetivo uma reflexão sobre o significado das temáticas ambientais para a sociedade contemporânea ou sobre os padrões de relação sociedadenatureza que têm estado presentes na história da civilização humana.

São exíguas as passagens ou reflexões mais sistematizadas que se referem diretamente ao processo educativo no seu sentido mais amplo. O resultado desse processo de análise revela que o mais comum é encontrarmos nos textos, ora de forma mais explícita, ora a partir de determinados elementos relacionados com o processo educativo, referências mais específicas sobre educação ambiental.

Em uma das raras passagens mais sistematizadas sobre processo educativo no seu sentido mais amplo, um dos textos enfatiza os elementos que são "caros" à perspectiva freireana, a saber, "o homem como sujeito de seu próprio processo educativo", o homem concreto considerado na sua dimensão espaço temporal, a educação para a liberdade e a atitude crítica do educador,

Para ser válida, toda educação deve necessariamente estar precedida de uma reflexão sobre o homem e de uma análise do meio de vida concreto a quem queremos educar (ou melhor dito: a quem queremos ajudar a educar-se) (...) A vocação do homem é a de ser sujeito e não objeto. (...) não existem senão homens concretos. (...) O homem é um (ser) de raízes espaço temporais (FREIRE, 1980, p.34 apud Tr 52). 
Ou então: a "[...] vocação ontológica do homem - vocação de ser sujeito" e a necessidade de considerarmos a concretude da realidade humana, o "contexto" no qual esse homem vive são também referenciados em um outro texto analisado (FREIRE, 1980 p.34 apud Tr 52); (MIZUKAMI, 1986 apud Tr45).

A análise das várias passagens dos textos que se referem mais especificamente à educação ambiental nos permite identificar, em alguns trabalhos, a relação, que tem sido reclamada por diversos educadores, entre o processo educativo e processos de mudanças sociais. Nesse caso, uma vez que se trata de processos educativos relacionados com a temática ambiental, destaca-se a perspectiva de alteração nos padrões de relação sociedade-natureza e, conseqüentemente, no atual quadro de degradação do meio ambiente que experimentamos,

(...) o processo educativo vem sendo considerado como um instrumento eficaz de transformação. (...) independente do modelo adotado para explicar o atual estado de agressão à natureza, o processo educativo é sempre apresentado como uma possibilidade de alteração desse quadro, isto é, como agente eficaz de transformação (CARVALHO, 2000 apud T16).

A relação entre o processo de transformação social e a perspectiva de uma educação libertadora é explicitada de forma clara em um dos textos do I EPEA,

Concebemos Educação Ambiental (QUEIROZ, 1997) como necessária para uma transformação social do mundo, devendo apontar para construção de novas formas de relacionamento dos homens entre si e com a natureza. A dimensão ambiental, neste caso, assume um caráter histórico-social, pois não visa apenas transformação dos indivíduos em relação à natureza, mas do conjunto da sociedade. Portanto, a compreensão dos problemas ambientais extrapola o âmbito da relação homem-natureza e passa necessariamente pelo estudo das questões mais amplas da sociedade. Dessas interações são 
produzidos processos de transformação da natureza e do meio social, no qual o homem, como ser histórico, encontra-se inserido (Tr39).

Em uma passagem posterior, esse texto afirma:

A nossa posição não é de neutralidade, pois no momento em que apontamos o caráter conflituoso da questão ambiental, estamos fazendo uma opção político-pedagógica por uma educação libertadora, que motive o homem a lutar pela transformação da sociedade transformando a si mesmo $(\operatorname{Tr} 39)$.

Os limites do processo educativo são mencionados de maneira tênue em um dos textos, possivelmente tendo como motivação muito mais a tentativa de reforçar o caráter e a força transformadora da educação do que a de alertar para os riscos de "otimismo pedagógico",

Embora exista entre os educadores uma compreensão generalizada de que não cabe à educação a responsabilidade por superar as mazelas sociais, econômicas e ambientais da sociedade, mudanças precisam e devem ser promovidas[...] (SORRENTINO, 1994 apud Tr68).

Em alguns textos, a referência a possíveis mudanças no processo social torna-se explícita, quando se menciona o papel da educação ou da educação ambiental nas transformações do "status quo" ou à "[...]transformação do sistema produtivo e do consumismo em uma sociedade baseada na solidariedade, afetividade e cooperação, visando à justa distribuição de seus produtos entre todos" (Tr70).

A relação entre processo educativo e mudanças no atual quadro de degradação do meio ambiente, no que se refere à melhoria da qualidade ambiental e qualidade de vida para a população como um todo, é enfatizada nos textos do I EPEA. A busca de possíveis caminhos para a solução de problemas ambientais é associada a esse caráter transformador da educação e da educação ambiental. Processos de "capacitação dos indivíduos para a solução de problemas ambientais" ou a "educação do cidadão para a solução de problemas 
ambientais" são vistos como sendo práticas intrínsecas, que marcam, identificam e caracterizam as atividades de educação ambiental. A possibilidade de a educação ambiental ser direcionada para a solução dos problemas concretos, ou para a busca de soluções práticas são, muitas vezes, apresentadas nos textos analisados. Vejamos alguns exemplos:

nesta Conferência [Conferência de Estocolmo (1972)], preconizava-se que se deveria 'educar para a solução de problemas ambientais (REIGOTA, 1994 apud Tr20).

ou ainda,

Educação Ambiental deve estar voltada para a recuperação, conservação e melhoria do meio ambiente e qualidade de vida da nossa e de todas espécies desta e das futuras gerações (SORRENTINO, 1993 apud Tr25).

Podemos observar que nos exemplos anteriores as referências tanto aos problemas ambientais como aos processos de recuperação, conservação e melhoria do meio ambiente são apresentadas de forma muito genérica. Em outros, no entanto, questões mais específicas são mencionadas como, por exemplo, quando se entende que a educação pode contribuir para a solução dos problemas relativos à produção de resíduos (Tr02 e Tr49) ou contribuir para a otimização do uso da água (Tr06). Cabe destacar que, pelo menos no caso dos textos citados que se referem à questão dos resíduos sólidos, a contribuição do processo educativo passa necessariamente pelo entendimento das relações entre consumo e produção de resíduos.

Associada às possibilidades de mudanças de "hábitos, posturas e comportamentos, que sejam capazes de promover o envolvimento em ações que busquem a melhoria da qualidade de vida" (T68), a possibilidade de mudança nas concepções dos indivíduos apresenta-se também como possível motor de transformação. A relação entre "mudanças das concepções das pessoas" e, conseqüentemente, "de suas 
relações com o mundo" (Tr57) assim como a necessidade de a educação ambiental enfrentar a "mudança de mentalidade sobre o modelo de desenvolvimento" vigente ( $\operatorname{Tr} 11)$ exemplificam tais perspectivas.

Merece destaque, ainda, o fato de algumas pesquisas apontarem para a possibilidade de práticas de educação ambiental provocar mudanças não apenas nas práticas educativas em geral como também nas próprias concepções sobre educação e sobre escola,

Percebemos pelos projetos desenvolvidos nas escolas que a E.A. pode contribuir para modificar as concepções de escola e de Educação (MAYER, 1988): de uma escola que transmite conhecimentos elaborados em âmbito externo para uma escola que constrói conhecimentos relevantes em âmbito local; de uma escola onde os objetivos estão vinculados exclusivamente nos conhecimentos (saberes) prontos e acabados, para uma escola que quer enfatizar os sentimentos, discutir valores, criar novos comportamentos e de uma escola estática que é modificada tardiamente pelos estímulos da sociedade, para uma escola que quer modificar a sociedade e que não aceita ser subalterna a outras instituições. (Tr40).

Ou ainda,

A tendência da E.A escolar é tornar-se não só uma prática educativa, ou uma disciplina a mais no currículo, mas sim consolidar-se como uma filosofia da Educação, presente em todas as disciplinas existentes e possibilitar uma concepção mais ampla do papel da escola no contexto ecológico local e planetário contemporâneo.(REIGOTTA, 1999 apud $\operatorname{Tr} 42)$.

Um outro texto $(\operatorname{Tr} 25)$ toma como base o pressuposto de que a possibilidade de se trabalhar, a partir das atividades de educação ambiental, "problemas concretos da sociedade, pode servir como um dos instrumentos para a transformação da escola burocrática em escola compromissada com o ensino integrado à vida". 
Um dos trabalhos apresentados no I EPEA poderia ser tomado como exemplo por elucidar uma perspectiva de transformação, explícita em alguns e implícita nas entrelinhas de outros,

Assim, se a educação é mediadora na atividade humana, articulando teoria e prática, a educação ambiental é mediadora da apropriação, pelos sujeitos, das qualidades e capacidades necessárias à ação transformadora responsável diante do ambiente em que vivem. Podemos dizer que a gênese do processo educativo ambiental é o movimento de fazer-se plenamente humano pela apropriação/transmissão crítica e transformadora da totalidade histórica e concreta da vida dos homens no ambiente(Tr46).

A análise que realizamos parece nos indicar que a relação entre o processo educativo, a educação ambiental e práticas transformadoras pode ser vista como uma tendência das pesquisas apresentadas no I EPEA. No entanto, a questão que vem sendo colocada desde o final da década de 80, parece-nos ainda pertinente e significativa: até que ponto a possibilidade de a educação ambiental provocar mudanças e reverter o atual quadro de degradação ambiental - não estaria correndo o risco de idealização ou mistificação? Algumas das pesquisas apresentadas no Encontro chamam a atenção para esse risco.

De qualquer forma, a análise dos textos permite-nos identificar uma dimensão da educação que vem sendo marcada, insistentemente, por vários autores, desde que foram propostas as possíveis relações entre contexto social, a temática ambiental e o processo educativo, qual seja, a natureza política da educação ambiental, a saber,

Partimos do pressuposto de que a educação Ambiental está imbuída de um conteúdo político e de que a ação educativa situa-se numa ampla e complexa relação de conflitos histórica, social e culturalmente condicionados (GUTIERREZ; PRADO, 1999 apud $\operatorname{Tr} 01)$.

Ou ainda, no trabalho Tr65, os autores consideram que a EA 
requer uma identidade política, embasada pelas lutas sociais e pelo movimento ambientalista que oportunizaram uma subversão de pensamentos e uma nova identidade aos/às educador@s (sic) ambientais, em especial à América Latina. Assim, o ambiente, tradicionalmente percebido como "adjetivo" da educação, confere um status político de significação diferenciada, tornando a EA como um verdadeiro substantivo composto de emancipação e lutas na construção de uma sociedade mais justa, com menos desigualdades sociais e com mais equilíbrio ecológico (Tr65).

A natureza política da educação ambiental se expressa em alguns textos a partir de elementos gerais e particulares que se complementam. De um lado, esse processo pode ser entendido "como instrumento de desvelamento social e de luta pela saúde" (Tr44), de outro, medida em que se reconhece que "são decisões políticas todas as que, em qualquer nível, dão lugar às ações que afetam o meio ambiente" (OLIVEIRA, 2000 apud Tr52). Expressa-se, ainda, quando se entende ser a educação ambiental um processo que possibilita a "apreciação da questão ambiental, sob sua perspectiva histórica, antropológica, econômica, social, cultural e ecológica, enfim, como educação política" $(\operatorname{Tr} 52)$.

Entendemos, ademais, como uma outra forma de expressão da perspectiva política da educação ambiental, as possibilidades que são expressas em alguns dos textos analisados quanto ao papel deste processo na construção da cidadania,

[...] a Educação Ambiental como experiência coletiva de construção de cidadania e participação nos processos decisórios torna-se estratégica para a tomada de consciência e a mobilização social capaz de transformar a realidade local $(\operatorname{Tr} 37)$.

Ou ainda, cidadania e responsabilidade social (JACOBI et al. apud 1998, T12) cidadania e a compreensão de "direitos, deveres para com os lugares e as pessoas à sua volta" (RUTKOWSKI, 1993 apud 
T13) são ingredientes que se somam na busca de melhores condições de vida e de padrões de relação "mais harmoniosa com a natureza".

Essas e outras passagens nos textos explicitam a dimensão política da educação ambiental. No entanto, as afirmações e indicações sobre tal proposição não esgotam a complexidade que esta perspectiva coloca. Apenas explicitar essa relação não nos parece suficiente para reconhecer todas as implicações teórico-metodológicas dela decorrente. Compreender a educação como possível motor de transformações sociais, significa conforme salienta Severino (2001), entendê-la na sua complexidade de prática social, como mediadora por excelência para as demais práticas que constituem a nossa "existência histórica". Conforme esse autor alerta, essa intrínseca relação entre o processo educativo e a dimensão política pode ser buscada nas condições reais de existência da sociedade humana, no fenômeno da sociabilidade como constitutivo do ser humano (SEVERINO, 2001). É essa condição de relacionalidade que garante ao ser humano construir a sua singularidade e ao mesmo tempo constituir-se nos grupos sociais como "sociedades políticas" (p. 52).

Dessa forma, não há outro caminho a não ser $o$ de explicitarmos e reconhecermos os limites da educação ou, nas palavras de um dos textos analisados, colocá-la "no seu lugar",

A preservação da natureza, a preservação do meio ambiente ou expressão que julgamos mais adequada - a preservação do mundo dos homens e do mundo das coisas é, pois tarefa que transcende os limites da educação ou, melhor dizendo, que a coloca no seu lugar - o da ação dos homens na sua pluralidade, isto é, o lugar do público, do político. Portanto, ação de homens livres (Tr16).

Entendemos que é nessa mesma direção que são encaminhadas as reflexões de Rodrigues (2001) anunciadas na introdução desse trabalho. A necessidade parece ser, assim, de questionarmos sempre sobre o significado e o "lugar da educação" nas nossas experiências humanas. Como salienta esse autor o "conhecimento só avança quando são colocadas sob suspeita, conclusões já assumidas como 
verdadeiras" (p. 233). É nesse sentido que se coloca a necessidade sempre de suspeitarmos das afirmações aligeiradas sobre a relação intrínseca entre o processo educativo e transformações sociais, entre educação e política ou educação e cidadania. $O$ grande risco segundo Rodrigues (2001) é o de ao entendermos que “....as questões referentes à Educação se acham esclarecidas, só caberiam a partir dessa posição interrogações de ordem prática. As nossas reflexões se limitariam às considerações de natureza pragmática e utilitária". As interpretações que fizemos a partir dos textos analisados indicam que não nos parece infundados os riscos de uma visão instrumentalizada do processo educativo quando relacionamos esta prática social com questões referentes à temática ambiental.

De qualquer forma, uma vez que educação e política se apresentam tão intrinsecamente relacionadas parece-nos significativo e pertinente perguntarmos sobre os entendimentos expressos nos textos analisados em relação a diretrizes e propostas para a concretização desta perspectiva. Sendo assim, procuramos nos textos analisados, a partir de fundamentações, justificativas, diretrizes, objetivos gerais e específicos para as práticas educativas e dos princípios metodológicos apresentados como orientadores para o planejamento e desenvolvimento de tais práticas indícios que pudessem nos auxiliar na construção de possíveis respostas a tal indagação.

\section{1 - Educação, educação ambiental e o processo de participação}

O processo de análise dos conteúdos dos textos permitiu-nos identificar como uma conseqüência - quase que natural - dos pressupostos presentes nas pesquisas e ensaios críticos analisados, uma diretriz muito geral, proposta em alguns trabalhos, qual seja, o processo de participação dos educandos.

É interessante observar que a participação assume diferentes significados em diferentes grupos de trabalhos. Em alguns desses trabalhos ela é vista como um princípio básico, como uma diretriz que garantirá que os objetivos propostos sejam alcançados: 
A participação é um dos princípios básicos da educação ambiental. A educação ambiental deve ser um processo participativo através do qual o indivíduo e a coletividade constroem valores sociais, adquirem conhecimentos, tomam atitudes, exercem competências e habilidades voltadas para a conquista e manutenção do meio ambiente ecologicamente equilibrado, num contexto de justiça social. (Tr57)

Vista ainda como um dos princípios básicos para a educação ambiental, a participação no processo de planejamento das ações educativas é entendida como um caminho para a interdisciplinaridade e integração,

Conforme os princípios básicos descritos pela EA, o planejamento das ações deve ser essencialmente participativo: professores, alunos, segmentos comunitários, agentes sociais de uma prática social em que cada um contribua com sua experiência acumulada, onde o planejamento participativo tornar-se-á "um instrumento para se alcançar a interdisciplinaridade pelo incentivo a uma postura integrativa”. (GUIMARÃES, 1995 apud Tr58).

No entanto, outros significados são atribuídos a este processo, ou seja, a participação pode ser vista como um valor que, assim como outros, tais como igualdade de direitos, respeito à diversidade cultural ou democracia, devem estar presentes nas propostas de educação ambiental (Tr11). Uma outra possibilidade veiculada em um dos textos (Tr12) é a de olhar para a participação como um objetivo da educação ambiental, ou seja, o desenvolvimento de atividades educativas relacionadas com o meio ambiente poderia promover "a participação consciente" dos educandos na "apresentação de sugestões e propostas para ações". Em um dos trabalhos essa perspectiva é assim apresentada,

A educação ambiental é um processo que consiste em propiciar às pessoas uma compreensão crítica e global do meio ambiente para elucidar valores e desenvolver atitudes que lhes permitam adotar uma 
posição crítica e participação ativa a respeito das questões relacionadas com a conservação e adequação dos recursos naturais $(\operatorname{Tr} 57$; $\operatorname{Tr} 75)$

Vale salientar, todavia, que a perspectiva mais comum nos trabalhos analisados é a de que em projetos de educação ambiental a participação seja vista como uma estratégia, que possa contribuir para o encaminhamento de um determinado problema. Assim, por exemplo, argumenta-se que

[...]a Educação ambiental tem se tornado cada vez mais importante como meio de buscar apoio e participação dos diversos segmentos da sociedade para a conservação e melhoria da qualidade de vida $(\operatorname{Tr} 36)$.

Esta é uma idéia recorrente nos textos analisados. Em outros trabalhos nos quais essa abordagem é adotada considera-se, por exemplo, que o estímulo à participação ajudará na busca de soluções para os diversos problemas ambientais $(\operatorname{Tr} 14, \operatorname{Tr} 25)$. Vista "como um veículo por excelência de condução de qualquer processo de participação e ou tomada de decisão (Tr37) ou como um caminho para o desenvolvimento de ações de "gestão ambiental" ou "como ponto de apoio para a conservação" (Tr50) a educação ambiental é entendida como uma "estratégia" para a participação e conseqüentemente como um caminho para solução de problemas,

$\mathrm{Na}$ gestão ambiental a participação de todos os indivíduos é primordial; ela que assegurará as profundas transformações que se estão gerenciando. Mas esta participação não se dá de forma totalmente espontânea; ela é aprendida. Desta forma, para que um sistema de gestão ambiental possa se tornar efetivo e ser interiorizado por todos os indivíduos envolvidos é necessário que um programa de e. a. acompanhe todo o processo de implantação e execução do sistema, visando, inclusive a sua continuidade $(\operatorname{Tr} 12)$. 
Por fim, a possibilidade de que essa participação se transforme em ação coletiva e politizada uma vez que o indivíduo "sensibilizado e na posse de novos conhecimentos [...] pode instigar e envolver outros indivíduos buscando a participação política (Tr14)ou a construção da cidadania",

[...] "a educação ambiental, não pode cair no imediatismo, mas, sobremaneira, deve ser incorporada de acordo com as realidades de cada região, com o envolvimento da comunidade, que assegure a construção de uma sociedade mais participativa e efetivamente cidadã" (SATO, 1999, p. 62 apud Tr52).

A proposta de uma educação ambiental que estimule a participação dos envolvidos leva a duas outras conseqüências: desenvolvimento da capacidade de tomada de decisões e a construção da autonomia e independência dos indivíduos e das comunidades regionais:

[...] considerando a importância da educação para o meio ambiente e a saúde, verifica-se a necessidade de uma prática em Educação Ambiental que 'orientada pela busca de maior independência e autonomia das pessoas, possa transcender o plano das normas comportamentais para encontrar na saúde, como expressão da qualidade de vida, o seu sentido principal' (Assis, 1999, p.25 apud Tr44).

Dessa forma, a criação de situações que envolvem "tomadas de decisão" (Tr19), a construção de "soluções em conjunto", o "estímulo à iniciativa" e "co-responsabilidade no processo de resolução dos problemas" (Tr06) são, também, fatores relacionados com o processo de participação.

\section{2 - Educação ambiental e interdisciplinaridade}

O caráter interdisciplinar da temática ambiental e da educação ambiental é um dos princípios metodológicos mais reconhecidos nos textos analisados, ora visto como característica da temática ambiental, 
Segundo SERRÃO (1999), alguns dos elementos que caracterizam a teoria e a prática correntes na Educação Ambiental e ressaltados pelos professores pesquisadores neste trabalho foram identificados por Hart (1981) e Charton (1990): o caráter interdisciplinar de suas temáticas, atingindo todos os níveis de escolaridade ; uma nova ética ambiental global. O fornecimento de informações aos estudantes sobre o ambiente, de maneira que eles possam desenvolver seu processo cognitivo, afetivo e comportamental, participando da solução de problemas ambientais complexos num ato de respeito e amor ao mundo natural e social." (Tr19, p.9),

ora entendido como fruto ou conseqüência de uma concepção de meio ambiente,

Todas essas experiências partem de uma concepção de meio ambiente em sua totalidade, considerando a interdependência entre o meio natural, o sócio - econômico e o cultural o que leva a uma abordagem pedagógica inter, multi e transdisciplinar (Tr72, p. 3).

A interdisciplinaridade é ainda apresentada em um dos textos como um princípio básico para o planejamento e desenvolvimento de propostas de educação ambiental,

No planejamento e oferta da disciplina consideramos como princípios formativos básicos em Educação Ambiental (EA) que "a questão ambiental na formação do universitário deve ser interdisciplinar, holística, crítica, interativa e voltada à solução de problemas da comunidade e à construção do conhecimento individual e coletivo", princípios apontados por Sorrentino (1995, 2000), bem como por Tilbury (1992), Mayer (1998), Sato (2000), dentre outros (Tr46).

O “diálogo interdisciplinar" promovido pela Educação Ambiental é apresentado em um dos textos analisados como uma forma de viabilizar "abordagens diversas que garantam uma percepção multifacetada da realidade". Além dessas possibilidades, uma outra 
perspectiva pôde ser identificada em um dos textos (Tr43), qual seja, o fato de a "interdisciplinaridade" ser considerada como categoria para análise de "princípios metodológicos de caráter pedagógico".

Não se pode dizer que tenhamos identificado nos textos que fazem referência à interdisciplinaridade um esforço em sistematizar referenciais ou explicitar os significados atribuídos a este termo. Em algumas passagens o termo interdisciplinar é utilizado no sentido de “...interação de diferentes conhecimentos científicos acerca da temática ambiental" (Tr09) ou como um "...incentivo a uma postura integrativa" (Tr58). É interessante observar que a perspectiva interdisciplinar é mencionada, em alguns dos textos analisados, como um processo intermediário à perspectiva multi ou pluridisciplinar e à perspectiva transdisciplinar, como, por exemplo, “....abordagem pedagógica inter multi - transdisciplinar" (Tr72) ou "enfoque pluri - inter transdisciplinar", deixando implícita uma conotação de ser esta um processo intermediário a essas outras perspectivas.

Em um dos textos, a partir de uma citação de CASCINO (1999 apud Tr43), chama-se a atenção para o fato de que a idéia de "integrar matérias e/ou conteúdos aos pares, aos trios de 'matérias', como geralmente ocorre em nossas escolas indica a precariedade da reflexão sobre esse conceito chave para a reconstrução da idéia de educação". Merece destaque ainda a relação que se estabelece em outro trabalho entre práticas educativas organizadas sob o paradigma da interdisciplinaridade nos cursos de graduação a possibilidade de "superação do paradigma racionalista da ciência moderna", de superação das "formas fragmentadas do pensar e agir nos cursos de graduação". Propõe-se, assim, a busca da "interdisciplinaridade radical", no conceito de Villaverde. Essa escolha implicaria, assim, na superação das "formas acadêmicas atuais de organização do ensino, da pesquisa e da extensão" ( $\operatorname{Tr} 43)$.

No entanto, mais uma vez vale aqui o alerta quanto à necessidade de questionarmos profundamente o sentido real de propostas ou termos que, dependendo do rigor com que são compreendidos em um dado momento, podem significar alterações significativas em nossas práticas, transformando-se em pouco tempo 
em modismos que, revestidos de um caráter mágico, perdem a sua eficácia na prática. Dessa forma, parece-nos fundamental questionar os sentidos atribuídos pelo senso comum à interdisciplinaridade.

Sem dúvida, há um reconhecimento de que

[...] o ambiente está integrado por processos, tanto de ordem física como social, dominados e excluídos pela racionalidade econômica dominante: a natureza superexplorada e a degradação ambiental, a perda de diversidade biológica e cultural, a pobreza associada à destruição do patrimônio de recursos dos povos e a dissolução de suas identidades étnicas; a distribuição desigual dos custos ecológicos do crescimento e a deterioração da qualidade de vida (Leff, 2002, p. 159).

Assim considerando "a problemática ambiental demanda a produção de um corpo complexo e integrado de conhecimentos sobre os processos naturais e sociais que intervêm em sua gênese e em sua resolução" (Leff, 2002, p.162).

As observações apresentadas em um dos textos analisados às quais fizemos referência são retomadas por Leff (2002) tendo em vista que o conhecimento exigido pela problemática ambiental "não é a soma nem a integração dos conhecimentos disciplinares disponíveis". O que se pretende é a transformação dos paradigmas tradicionais e a produção de novos conhecimentos, o diálogo, hibridação e integração de saberes, bem como a colaboração de diferentes especialidades, propondo a organização interdisciplinar do conhecimento (p. 162). Trata-se, assim, segundo o autor, de buscarmos a construção de um "saber ambiental". Este processo depende, antes de mais nada, da aceitação e apreensão da complexidade ambiental por meio dos nossos esforços de compreensão dos padrões de interação com a natureza. Esta é a primeira etapa e condição para o necessário diálogo de saberes, que nos exige a consideração da subjetividade e dos valores (Carvalho, et al, 2003). Apreender essa complexidade implica um processo de desconstrução e reconstrução do pensamento; desconstrução do pensado para se pensar o não pensado (Leff, 2002, 
p. 192). A perspectiva interdisciplinar ganha assim uma dimensão transformadora tanto em relação aos processos de produção do conhecimento quanto de sua natureza e de sua socialização.

\section{3 - Educação ambiental e valores}

A reconhecida relação entre o processo educativo e a construção de valores éticos e estéticos presentes nos trabalhos analisados abre caminhos para se pensar em uma educação ambiental voltada para mudanças nos atuais padrões axiológicos. Na perspectiva apresentada por alguns trabalhos, o que se pretende é que a construção de novos valores, de uma nova ética relacionada com a vida, no seu conceito mais amplo e com natureza de maneira geral, seja um dos princípios metodológicos que orientam os trabalhos em educação ambiental. A possibilidade da construção de uma nova ética em relação à vida é, assim, uma utopia a ser alcançada:

Necessitamos de uma Educação voltada para a construção de um padrão "mais ecológico" de perceber o mundo, como instrumento formador das bases e dos valores necessários para uma nova ética com relação à vida $(\operatorname{Tr} 35)$.

A educação ambiental só pode ter sentido a partir de encaminhamentos éticos que resultem no questionamento de valores no próprio educador e, conseqüentemente nas pessoas a quem ele educa. Acima de qualquer coisa, a educação ambiental é um movimento ético que leva o indivíduo a revisar sua postura em relação ao seu meio $(\operatorname{Tr} 50)$.

É preciso distinguir uma educação conservacionista de uma Educação Ambiental. A primeira é aquela cujos ensinamentos conduzem ao uso racional dos recursos naturais. Já a Educação para o meio ambiente implica também uma mudança de valores, uma nova visão de mundo, o que ultrapassa bastante o universo meramente conservacionista. (BRÜGGER, 1994 apud T54). 
No entanto, além dos valores reconhecidos como mais diretamente vinculados ao ideário ambientalista e ainda não vistos como parte dos padrões éticos da sociedade contemporânea, outros já reconhecidos como parte constitutiva do sujeito ético são mencionados em alguns textos, a saber:

É necessário que a Educação ambiental seja pautada nos "valores da solidariedade, da cooperação, do respeito, do compromisso com o coletivo, da participação, da responsabilidade com o social GARCIA, 1993, apud Tr10).

Ou ainda:

A EA visa promover um espírito de solidariedade, cooperação e responsabilidade entre os indivíduos, os grupos sociais e as nações (Tr06).

Entendemos como relevante a relação estabelecida por Rodrigues (2001) entre liberdade, autonomia e a construção do sujeito ético. Para esse autor, a construção da autonomia depende de uma atuação do sujeito de forma independente e participativa na vida social. Essa possibilidade passa por sua capacidade "de estabelecer juízos de valor e assumir responsabilidades pelas escolhas. Dessa forma, "o fundamento ético da humanidade se assenta no tripé constituído pelo reconhecimento de si mesmo como sujeito (individualidade), na liberdade e na autonomia". Mais uma vez a educação é vista como uma possibilidade para que esses valores sejam incorporados. No entanto, essa possibilidade só se efetiva se construirmos condições políticas para tal.

\section{4 - Educação ambiental e a relação local-global-local}

Em alguns textos, fica clara a proposta de que os trabalhos em educação ambiental poderiam considerar a possibilidade de partir de situações mais imediatas, identificando problemas que envolvam 
diretamente as comunidades locais e regionais como uma orientação metodológica. É relevante notar que, de um lado, em alguns desses trabalhos, parece-nos que a ênfase para o tratamento de questões mais locais e regionais não se restringe a apenas uma possibilidade metodológica, vista como ponto de partida para as propostas educativas. Nessa perspectiva, os textos acabam por não fazer referência à necessidade de se considerar o mais imediato espacialmente como um procedimento que possibilite a compreensão da temática ambiental em uma perspectiva mais ampla, relacionando-a com dimensões e fenômenos em escalas espaciais mais amplas:

Estratégias da ação educativa nos planos formal e informal - diretrizes: (a) problemas locais devem ser o ponto de partida para planejamento dos programas de educação ambiental; (b) a comunidade local organizada ou não, deve participar da identificação desses problemas e dos processos de planejamento e implementação dos programas; (c) programas devem buscar parcerias nas instituições educacionais e ambientais; (d) os programas devem buscar sustentabilidade, formando agentes multiplicadores na comunidade local (Tr72).

Por outro lado, alguns trabalhos que se referem a esse princípio metodológico enfatizam a necessidade de que olhar para a realidade local mais próxima não pode nos impedir uma articulação dessas questões pontuais com aspectos mais globais de determinada problemática:

[...] a educação ambiental busca um novo ideário comportamental, tanto no âmbito individual, quanto coletivo. Ela deve começar em casa, ganhar as praças e as ruas, atingir os bairros e as periferias, evidenciar as peculiaridades regionais, apontando para o nacional e o global. Deve gerar conhecimento local, sem perder de vista o global, precisa, necessariamente, que envolva pais, estudantes, professores e comunidade. É um passo fundamental para a conquista da cidadania (OLIVEIRA, 2000 apud Tr52). 


\section{5 - Educação e conflitos socioambientais.}

Parece-nos pertinente apontar um importante aspecto mencionado em três textos $(\operatorname{Tr} 19, \operatorname{Tr} 20$ eTr46) do "corpus documental" dessa pesquisa Trata-se do potencial representado pelos conflitos socioambientais como princípio metodológico para os trabalhos em educação ambiental. Em um desses trabalhos, a questão do conflito é apresentada a partir de uma citação na qual o autor entende a educação ambiental como

Una formación que dote de herramientas intelectuales para interpretar de mejor manera la realidad, que rechace todo tipo de dogmatismos. Una formación que aborde el conflicto. Ello exigirá para los países del Tercer Mundo el establecimiento de estrategias propias. No copiadas, no reactivas ni contestarias, sino estrategias profundamente arraigadas con nuestra manera de ver nuestros problemas y necesidades. Una estrategia que nos permita hacer teoría, porque hasta eso pareciera que nos ha sido vedado; una estrategia tal, en la que el maestro y alumno deban dar su máximo esfuerzo. Solo asi podremos salirnos del pernicioso círculo de la injustificada autocomplacencia o de la derrota anticipada (Gaudiano, 1997 apud Tr46).

Embora essa perspectiva não leve necessariamente a posições pós-críticas, ela tem o potencial, conforme propõe Carvalho (2005), para questionar vários pressupostos presentes no que poderíamos denominar de senso comum do ideário ambientalista, principalmente ao colocar em questão conceitos como "harmonia nas relações sociedade-natureza", "equilíbrio da natureza", "visão holística", todas elas resultantes de análises sistêmicas e funcionalistas da natureza (p.12). Ao mesmo tempo, parece-nos instigante a possibilidade de que a análise de temas controversos relacionados com a temática ambiental ou de conflitos socioambientais aponte para os limites das perspectivas tradicionais, exigindo a consideração de novos modelos interpretativos para apreender a complexidade ambiental 


\section{3 - Para além das tendências críticas em educação?}

Uma vez que as tendências críticas em termos de propostas pedagógicas parecem marcar posição nos textos analisados, parece-nos pertinente indagar se nesses trabalhos podem ser encontradas evidências ou indícios que apontem para as influências das chamadas teorias pós-críticas ou pós-estruturalistas nas teorias educacionais.

Nesse sentido, parece significativo o fato de um dos textos chamar a atenção para a possibilidade de que alguns elementos do campo dos Estudos Culturais possam ser incorporados no desenvolvimento da educação relacionada com a temática ambiental. De acordo com o texto,

Uma Educação Ambiental menos pautada na intencionalidade de levar informações e mais no resgate das histórias de domínio da oralidade. "Narrativas" que poderiam fazer emergir algumas relações sociais esquecidas, silenciadas (...) nos permitindo questionar relações sociais atuais. Uma Educação Ambiental, menos imbuída, de levar consciência (Razão) aos sujeitos e mais preocupada em traçar problematizações de ordem subjetiva, ou seja, de questionar processos de subjetivação em operação na comunidade, ou seja, problematizar relações de poder envolvidas na produção dos sujeitos naquela localidade" (Observação do autor - "textos provenientes do campo dos Estudos Culturais Tr02).

Cumpre destacar que o chamado campo dos Estudos Culturais, que toma a "centralidade da cultura" na constituição da vida social, poderia aqui ser visto como uma tentativa de interpretar práticas sociais não com o referencial das interpretações mais tradicionais, mas procurando explorar o significado do termo "cultura" não apenas como conjunto de coisas, mas como processos e um conjunto de práticas (Wortmann, 2001). Nesta proposta a questão é não só a de ampliar o espectro do que vinha sendo considerado como parte da esfera cultural, mas, também, procurar "transitar nos meandros e nas redes em que se institui, e onde circula, dinamicamente, o saber/poder" (p.37). 
Um outro trabalho apresenta claramente determinados aspectos que nos permitem evidenciar proposições que apontam para perspectivas pós-modernas. Algumas passagens reforçam essa perspectiva, tanto pelas idéias que encerram quanto pelos autores que as fundamentam. Vejamos:

Queremos [...] entender como esses valores compõem alguns episódios das práticas escolares, sobretudo em situações nas quais foi estimulado o diálogo entre os conhecimentos científicos e os de outros campos culturais. Acreditamos que o diálogo entre as diferenças, assim como afirmam Burbules e Rice (1993, p. 182) ${ }^{2}$, ao falarem dos pós-estruturalistas, coloca-as em processo de interação constante, de forma que cada uma delas muda na medida em que tenta fixar o outro $(\operatorname{Tr} 19)$.

Ou ainda, em uma passagem posterior faz-se referência à proposta de Deleuze e Guattari em relação a

[...] um novo paradigma para a organização do conhecimento, contraposto ao arbóreo (linear) denominado rizomático. Dos seis princípios básicos que o regem, dois deles nos são bastante inspiradores na produção deste texto: o princípio da heterogeneidade e o da multiplicidade, com os quais podemos negar a hierarquia e a unidade da árvore; essa imagem é interessantíssima, pois foi perseguida por nós no seu conhecer por alunos e professores e, neste instante, teoricamente torna-se refigurada no contraste com o rizoma $(\operatorname{Tr} 19)$.

Merece registro o fato de essas tendências terem sido representadas nas mesas redondas realizadas no I EPEA. Nos anos

Vale registrar que o artigo de Burbules e Rice, citado no texto, é capítulo do livro "Teoria Crítica em Tempos Pós-modernos" organizado por Tomaz Tadeu da Silva, publicado em 1993 pela Editora Artes Médicas 
posteriores a este evento, podemos observar uma abertura e aprofundamento no campo dos Estudos Culturais e novas perspectivas de relação entre o processo educativo, a cultura e o saber/poder. Ganham força as abordagens que buscam compreender as relações entre educação e multiculturalismo, o diálogo entre as diferenças, as práticas subjetivas, as práticas discursivas, o diálogo entre os saberes, e outros. A relação entre essas diferentes possibilidades e a produção teórica na área da Educação Ambiental passa, assim, a ser um instigante campo de investigação.

\section{Considerações Finais}

Da análise sobre as concepções de educação e de educação ambiental presentes nos trabalhos apresentados no I EPEA, em julho de 2001, tanto nos relatos de pesquisas quanto nos ensaios teóricos, pudemos constatar que tais concepções nem sempre estão apresentadas de forma explícita. Parece que as concepções aqui buscadas eram, muitas vezes, dadas como supostas e, talvez por isso, não explicitadas. Assim, foi necessário enveredar pelos textos, buscando elementos que pudessem dar respostas às nossas indagações.

Constata-se ainda, com certa freqüência nos trabalhos analisados, uma tendência já identificada pela literatura sobre a produção teórica em Educação Ambiental, ou seja, a ausência de proposições mais sistematizadas e teoricamente fundamentadas sobre $\mathrm{o}$ processo educativo. Assim, por vezes, aquilo que é o substantivo perde o seu espaço desintegrando-se no adjetivo, que qualifica, porém carece de substância, ou seja, do essencial.

Os trabalhos que explicitam concepções de Educação ou de Educação Ambiental são também aqueles que fazem uma opção por um referencial teórico mais definido e com maior consistência.

No que diz respeito às tendências pedagógicas, há evidências, nos trabalhos analisados, de uma perspectiva crítica para a Educação Ambiental. Porém, considerando o espectro existente na literatura sobre o tema, na área da filosofia ou mesmo da educação, poucos são os trabalhos que definem ou explicitam a opção assumida. O que é ser 
crítico, afinal? Que fundamentos são apresentados para justificar as posturas ditas críticas de forma a evitar a superficialidade, os jargões e a linguagem panfletária? Constatamos nos trabalhos analisados a presença de autores que fundamentam opções pedagógicas, contudo, apesar de referidos, há pouca sistematização sobre eles. Paulo Freire é um dos autores que aparecem com uma freqüência maior; José Carlos Libâneo, Dermeval Saviani, Moacir Gadoti e Carlos Rodrigues Brandão também são citados, porém pouco explorados.

Da análise empreendida, pudemos constatar uma relação presente entre o processo educativo, a Educação Ambiental e a transformação social. Tal relação se manifesta em determinados textos com base na convicção da necessidade de participação em atividades e instâncias da sociedade exercendo e experienciando, com isto, a cidadania e, ao mesmo tempo, buscando interferir no quadro de degradação do meio ambiente com o fito de melhorar a qualidade ambiental e a conseqüente qualidade de vida. A Educação Ambiental é também, por vezes, direcionada para a solução de questões práticas, imediatas e locais.

A centralidade da dimensão política nos processos educativos relacionados com a temática ambiental se expressa de forma acentuada nos textos analisados. Outras sínteses que têm sido elaboradas sobre a produção teórica em educação ambiental, assim como a análise de práticas educativas, têm apontado para esta característica que consideramos fundamental. No entanto, a intencionalidade em nossas práticas de formação de seres humanos só pode se concretizar a partir da reciprocidade dessa dimensão política, tão cara aos educadores ambientais, com outras duas dimensões: a de conhecimentos e a de valores (éticos e estéticos) (Carvalho, 2000; Severino, 2001). Dessa forma, as diferentes tentativas de privilegiar determinados enfoques em detrimento da complementaridade e reciprocidade dessas diferentes dimensões da realidade humana acabam por não sustentar o projeto de vincular a educação ambiental aos processos de transformação social.

Gostaríamos ainda de chamar a atenção para dois outros aspectos da análise por nós empreendida. Em alguns trabalhos, ao se fazer referências aos objetivos da Educação Ambiental, processos de 
"transmissão de conhecimentos" e de "mudanças de comportamento" são enfatizados. Não se trata de chamar a atenção para tendências quantitativas no conjunto dos textos, mas para a ênfase dada a tais terminologias. Assim, "estimular comportamentos adequados", ou "fomentar a elaboração de comportamentos positivos de conduta", ou ainda, "promover condições básicas para que o ser humano assuma atitudes e comportamentos desejáveis em relação ao meio ambiente" são associados em alguns textos a objetivos da educação ambiental.

Tanto em relação a esses processos de "mudança de comportamento" como àqueles de "transmissão de conhecimentos", a hipótese que nos parece plausível em relação a determinados textos é a de que não se trata apenas de resquícios lingüísticos associados a vícios de linguagens do senso-comum pedagógico. O lugar e o destaque dado, às vezes, a esses processos permitem-nos perguntar até que ponto perspectivas fortemente vinculadas a tendências pedagógicas "tradicionais" ou "tecnicistas" não têm acompanhado a nossa prática, reflexão e mesmo tentativas de produção de conhecimento em educação ambiental.

Outro dado presente na análise foi o caráter reducionista da ação educativa por vezes constatado em alguns trabalhos. Neles, a educação é considerada como um instrumento ou veículo para a consecução de determinado fim específico. Essa redução da educação a um aspecto específico pode comprometer a sua natureza. Exemplo desse tipo pode ser encontrado quando se pensa em uma Educação Ambiental voltada para a solução de problemas relacionados a resíduos ou ao adequado uso da água. Essas são situações concretas em que a Educação Ambiental corre o risco de ser instrumentalizada, assumindo assim uma perspectiva pragmática.

Finalmente, sem querer assumir uma posição antropocêntrica, não se deve deixar de ressaltar o foco principal da ação educativa, que é o humano considerado a partir das diversas possibilidades de suas relações: consigo, com o outro (sociedade), com o meio (natureza). 


\section{Referências Bibliográficas}

BARDIN, L. Análise de Conteúdo. Tradução de Luís Antero Reto e Augusto Pinheiro. Lisboa: Edições 70, 1991.

BOGDAN, R.C. e BIKLEN, S.K. Investigação Qualitativa em Educação - uma introdução à teoria e aos métodos. Tradução de Maria João Alvarez, Sara Bahia dos Santos e Telmo Mourinho Baptista. Porto: Porto Editora, 1994.

CARVAlHO, L. M. Formação de Professores em Educação Ambiental. IN: MEC. Panorama da Educação Ambiental no Brasil. Brasília: MEC, SEF., 2000.

CARVAlHO, L. M; CAVAlARI, R. M. F.; SANTANA, L. C. O Processo de Ambientalização Curricular da UNESP-Campus de Rio Claro: diagnóstico e perspectivas. In: Gelli, Ana Maria. (Org.). Ambientalização Curricular de los Estudios Superiores. 3. - Diagnóstico de la Ambietnalización Curricular. 01. ed. Girona, v. 3, p. 171-207, 2003.

KANT, E. Sobre a Pedagogia. Tradução de Francisco Cock Fontanella. 3.ed. Piracicaba:Editora UNIMEP,2002.

RODRIGUES, N. Educação: da formação humana à construção do sujeito ético. Educação \& Sociedade, ano XXII, n. 76, Outubro/2001.

ROUSSEAU, J. J. Emílio ou da Educação. São Paulo: DIFEL, 1973.

SEVERINO, A.J. Educação, sujeito e história. São Paulo: Olho d’ Água, 2001. 